\title{
Innovation and International Entrepreneurship: \\ Will the Digital Platform Serve All?
}

\author{
Hussain G. Rammal \\ UTS Business School, University of Technology Sydney, \\ Haymarket City Campus PO Box 123 Broadway NSW 2007, Australia
}

Corresponding author: hussain.rammal@uts.edu.au

\section{ABSTRACT}

The link between knowledge, innovation, and technology, as understood in extant literature, tends to emphasize a digital, high-tech platform for the implementation of innovative ideas. This paper challenges this view and details why relying solely on digital platforms and innovation may not let companies reach their full potential. Using examples of frugal innovation, this paper recommends that entrepreneurs need not limit their ideas by focusing only on digital and technology driven innovation, and to consider the infrastructure realities of the developing economies.

\section{Keywords:}

entrepreneurship; disruption; digital; frugaal innovation 


\section{INTRODUCTION}

The terms innovation and entrepreneurship are often used together to describe the distinct nature of entrepreneurial activities. Much of the entrepreneurship literature discusses the notion of disrupting the status quo of business activities, and to introduce new ways of doing things. Schumpeter called this disruption creative destruction and highlighted this cyclical destruction and reconstruction of business to be the primary purpose of entrepreneurs (Schumpeter, 1934; 1942).

The digital platform provides opportunities for entrepreneurial ventures to take advantage of technology and take their business to the global market to not only innovate and introduce products and processes but also to challenge the market position of large firms. In this vein, we have witnessed the rise of international entrepreneurial and born global firms that are primarily small and medium enterprises.

However, not all innovation has to be technology-based or digital. In fact, many non-digital innovations tend to have a broader global appeal than digital innovations. This paper conceptualizes the relationship between innovation and international entrepreneurship and the role of, and reliance on technology and digital platform. Following the introduction, the next section provides an overview of International Entrepreneurship and depicts the relationship between knowledge, innovation, and technology. The paper then discusses some of the innovative ideas that have emerged from developing economies, and the paper concludes by identifying some areas for future research.

\section{IITERATURE REVIFW}

\section{International Intrepreneurship}

The majority of the literature on the internationalization of firms has its base in the Uppsala model, which states that firms internationalize gradually by entering markets which whom they share low geographic and psychic distances (Johanson \& Vahlne, 2009). According to the theory, the elements of shared history and physical proximity reduce the liability of foreignness that the firm can face if it internationalizes into markets that are distant from its home. The gradual process means that once firms have gained sufficient experience in international markets, they would start moving into more distant markets (Rammal \& Rose, 2014). The International Entrepreneurship literature has evolved, and the internationalization process it captured has challenged this traditional thinking. In particular, the experience of the Born Global (BG) firms demonstrates that the internationalization process is neither time or region bound (Cavusgil \& Knight, 2015).

BGs, also known as early internationalizing firms refers to firms that internationalize from the inception or very soon after. These firms deliberately target the slobal market, and the rapid internationalization is their way of securing a share of the market before competitors do (Dow, 2017). These BGs tend to be small and medium enterprises, and this provides them with the flexibility that larger firms may lack. What makes the BG firms unique is the inherent nature of the products and services that they offer. Hennart (2014) refers to these firms as accidental internationalists and argues that many $B G$ firms are technology-driven, and given this background, the internationalization 
process is a natural progression. These views pose several questions for researchers to consider. Do technology-driven firms have to originate from developed economies? Does innovation have to be technology-driven and or digital?

To answer these questions, the relationship between knowledge, innovation, and technology needs to be discussed in the context of entrepreneurship.

\section{Knowledge, Innovation, and Technology}

The terms "knowledge economy", "knowledge management", "knowledge creation", and "knowledge transfer" are often used to describe the changing nature of business and the transformation towards a digitally-connected economy. How this knowledge evolves into innovation, and its relationship with technology needs further elaboration.

Knowledge refers to one's familiarity with or understanding of facts, information, or skills. Although this definition seems to suggest that knowledge is a basic rather than an advanced skill, the fact is that knowledge can be categorized as explicit or tacit. Explicit knowledge includes information that can be transferred easily to individuals and can take the form of instruction manuals and other documents. Tacit knowledge is more difficult to understand, transfer, and apply. This is in part because tacit nature is implicit, held by individuals, and difficult to transfer through written words in instruction manuals or guides. The transfer of this knowledge requires programs and structures that facilitate the exchange of information between individuals, and this is usually done by working together or organizing dedicated training workshops. By working together, individuals can learn from each other, and this allows the tacit knowledge to be understood and shared.

Nonaka and Takeuchi's Socialization, Externalization, Combination, and Internalization (SECI) model explains this process in detail (Nonaka \& Takeuchi, 1995). According to the SECI model, the first step in transferring tacit knowledge requires changing it from its implicit nature to become explicit, and this requires individuals to work together and is known as socialization. Once the individual has gained the knowledge, they would attempt to externalize it by converting it into words and producing relevant documents and manuals. In the third step, these externalized documents are merged with existing manuals and documents to create new knowledge that is specific to the role and needs of the individual and the organization. In the final stage, the individual absorbs and applies the new knowledge to their work, and in this way, it becomes their tacit knowledge.

Armed with this new knowledge, individuals or groups of individuals can identify new ideas or ways in which existing processes can be made more efficient. Innovation is this identification of ideas and lies at the very heart of entrepreneurial activities. For entrepreneurs and entrepreneurial ventures like start-ups, their small size means that they have to innovate and offer a new idea or a new way of doing things. This innovation or disruption to the status quo is critical for the survival and success of the ventures.

For the innovation to be successful, it has to be supported by appropriate technology, that is, the relevant tools and machines required for the practical imple- 
mentation of the innovation. A mismatch between the technological infrastructure and innovation could result in a low-level effort, leading to the failure of the idea. Figure 1 illustrates this relationship.

\section{Barriers to Innovation}

It is therefore imperative that entrepreneurial innovative ideas are launched in markets that can support the idea through appropriate technology infrastructure. Innovative ideas have a limited time in which the returns from it can be maximized before they are replicated and copied, and lose their uniqueness. Hence, the tacit knowledge leading to the innovation needs to be transferred rapidly to other markets. The fastest way of achieving this is through the socialization element discussing earlier in the SECI model. This means that the entrepreneur who has the tacit knowledge needs to enter the territory of the host country and work with others who can help make the innovation idea a reality.

In theory, this seems like a simple task. However, government restrictions on the movement of individuals for work purposes can limit the transfer and application of the tacit knowledge. According to the World Trade Organization's General Agreement on Trade in Services, the government can permit or limit the entry of professionals entering their market under the Mode 4 form of service supply. For entrepreneurs and innovators, this restriction limits their ability to transfer their knowledge effectively. While this may help protect domestic firms

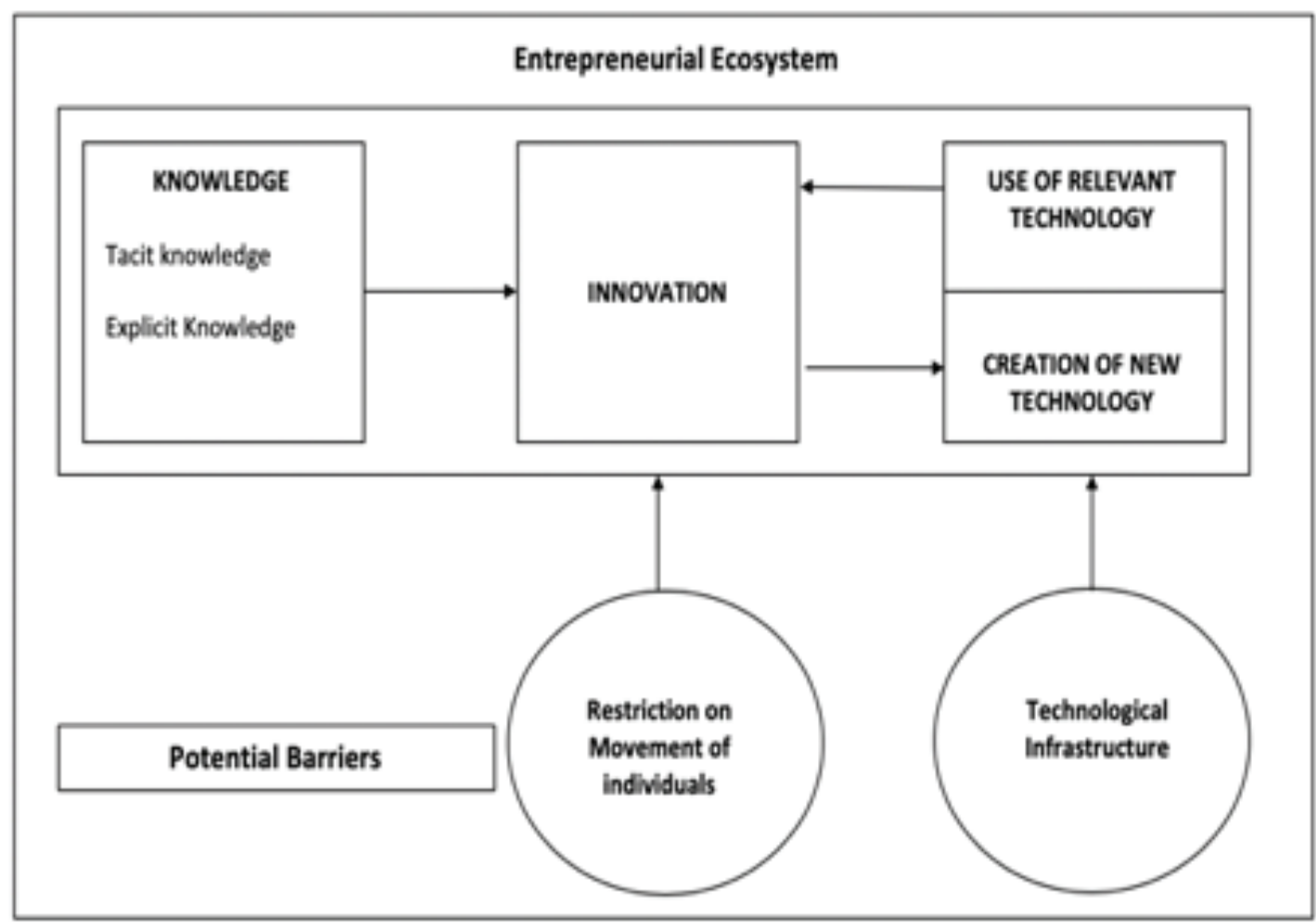

Figure 1. Relationship between Knowledge, Innovation, and Technology 
and entrepreneurs from foreign competition, in the long-run, the lower levels of knowledge acquisition and absorption by local entrepreneurs would be harmful for innovation in the host-countries.

But do innovative ideas have to rely on new and advanced technology or be digital in nature to be successful? We discuss these issues in detail in the next section.

\section{DISCUSSION}

\section{Innovation In Developing Economies}

A common misconception is that an idea is not innovative if it not technologybased or digital. This belief creates the impression that innovative ideas will originate from developed or tech-based economies. Many entrepreneurial ventures focus on tapping into the digital realm in order to develop ideas that can be described as innovative. This approach seems counterproductive as the final output of the innovation would be limited to primarily high-income consumers who would be able to afford these technology-based products.

The reality is that the majority of the world's consumers are based in the developing economies, where the availability and use of technology differ from that in the developed world. Global firms are, therefore seeking ideas that are innovative and not necessarily linked to technology or digital platforms. A good example of such innovation is frugal engineering, a term coined by Carlos Ghosn, the then head of Renault, to explain the phenomenon he observed in India, where engineers would focus on reducing costs by removing steps from a process or finding most cost-efficient alternatives for certain parts. The savings that were achieved from this innovative thinking led to
Renault opening a manufacturing plant in India to take advantage of this cost-reducing mindset.

Similarly, electronic-based innovative products can have a limited appeal in rural areas in many developing countries where the supply of electricity is frequently disrupted. In such markets, connected devices and emphasis on the internet of things holds little value. Innovative ideas that address the problems faced by these consumers, which can also include the base of the pyramid market, are more likely to find the success that is rapid and sustainable. The Mitticool refrigerator is an example of such innovation. We live in an age where internet-enabled refrigerators with touch screen technology are capable of streaming television shows and movies, and can also digitally connect to supermarkets to order consumables that the fridge detects needs to be replenished. Nevertheless, these technologies are neither relevant nor affordable for the majority of the world's consumers. In 2005, Mansukhbhai Prajapati, a potter in India, came up with the idea for a refrigerator that worked without electricity (Mitticool, 2019). The fridge, which is made of terracotta clay, can be cooled by filling its chamber with water and keeps milk, fruit, and vegetables fresh for days. In 2010, Prajapati was named by Forbes as one of the world's top 7 rural entrepreneurs, and the product was seen as an example of frugal innovation.

These examples prove that not all innovation emerges from developed economies. Looking at the advanced technology-driven digital innovation also suggests that firms from developing economies are rapidly gaining knowledge through acquisition of well-established brands 
(Lenovo's acquisition of IBM or Tata's acquisition of Jaguar and Land Rover), or in some cases generating new knowledge (for example, Alibaba.com and Tencent).

\section{CONCLUSION}

IMPLICATIONS FOR RESEARCH AND PRACTICE

This paper highlights the relationship between knowledge, innovation, and technology. The rapid pace at which automation is being integrated into business practices in many economies is forcing entrepreneurs to think about digital innovation. However, this transition to automation is not taking place evenly, with the largest consumer groups found in the base of the pyramid is living in countries where the technological infrastructure is still in its infancy and cannot support advanced digital products.

For entrepreneurs and entrepreneurial firms (including large firms that demonstrate intrapreneurship), limiting their ideas to digital platforms means that the majority of the world's consumers would not be targeted. As highlighted in this paper, there is an opportunity to think about innovation in more in terms of solutions and advancement and improvement of the lives of individuals rather than measuring success in terms of tech- nology. This difference in mindset makes the consumers the central focus of the innovation, and entrepreneurs are, therefore, more likely to consider their needs and look at existing technology in particular regional markets to come up with relevant solutions.

This attitude towards technology also has implications for research. Future researchers need to develop ways to measure the true potential of an innovation by calculating how many people are affected by their innovation compared to the cost of developing new technologies. This approach can help entrepreneurs determine whether existing technologies provide a more efficient and appropriate platform for entrepreneurs to deliver their innovative ideas.

Entrepreneurs, due to the small size of their operations, have to think slobally. By limiting the appeal of their innovative ideas to only developed or developing economies means that their ideas can be replicated by competitors and applied with changes in other parts of the world. Therefore, entrepreneurs have to think about how their ideas can be modified to fit the technological infrastructure of the market and the needs of the consumers. The ability to adapt and deliver is key to the success of the entrepreneurial venture. 4 


\section{RFFERENCES}

Andersson, U., Dasí, À., Mudambi, R. \&e Pedersen, T. (2016). Technology, innovation and knowledge: The importance of ideas and international connectivity. Journal of World Business, 51(1), 153-162.

Cavusgil, S. T., \& Knight, G. (2015). The born global firm: An entrepreneurial and capabilities perspective on early and rapid internationalization. Journal of International Business Studies, 46, 3-16.

Dow, D. (2017). Born global firms and accidental internationalists: Has Hennart (2014) opened a can of worms? Review of International Business and Strategy, 27(3), 286-30\%.

Hennart, J.F. (2014). The accidental internationalists: a theory of born globals. Entrepreneurship Theory and Practice, 38(1), 117-35.

Johanson, J., \& Vahlne, J.-E. (2009). The Uppsala internationalization process model revisited: From liability of foreignness to liability of outsidership. Journal of International Business Studies, 40, 1411-1431.

Mitticool (2019). About us. https://mitticool.com/about-us/. Accessed online on 5 September 2019 .

Nonaka, I., \& Takeuchi, H. (1995). The knowledge-creating company: How Japanese companies create the dynamics of innovation. New York: Oxford University press.

Rammal, H. G., \& Rose, E. L. (2014). New Perspectives on the Internationalization of Service Firms. International Marketing Review, 31(6), 550-556.

Schumpeter, J. A. (1934). The Theory of Economic Development: An Inquiry into Profits, Capital, Credit, Interest and the Business Cycle: Transaction Publishers.

Schumpeter, J. 1942. Capitalism, Socialism, and Democracy. New York: Harper \&e Bros. 